\title{
Class II, Division 1 Malocclusion treated with the Andresen Appliance followed by Fixed Orthodontics
}

\author{
${ }^{1}$ Oscar M Antelo, ${ }^{2}$ Thiago M Meira, ${ }^{3}$ Adriana Iturralde, ${ }^{4}$ Lara K Guimarães, ${ }^{5}$ Orlando M Tanaka
}

\begin{abstract}
Introduction: Mandibular retrognathism is the most common feature in class II malocclusions. Functional appliance therapy focuses on reducing the increased overjet and overbite, establishing better conditions for mandible growth response in phase I. Phase II corrects the position of the teeth and gives an adequate stable occlusal relationship.
\end{abstract}

Aim: (1) To describe a class II, division 1 malocclusion treated with the Andresen activator in a growing patient followed by comprehensive orthodontic fixed appliances, and (2) to take advantage of both approaches performed immediately one after the other in adolescence to obtain better and stable results without tiring the patient and parents, prolonging the treatment time.

Case report: A 13-year-old female patient presented with a class II, division 1 malocclusion with increased overjet and deep overbite, due to mandibular retrognathism. She wore the Andresen activator approximately 12 to 14 hours per day during afternoons and nights for 9 months, followed immediately by comprehensive fixed appliances for an extra period of 1 year.

Conclusion: Clinical results showed that class II, division 1 malocclusion was corrected, overjet and deep overbite were reduced to normal parameters, and convex profile was improved to a straight one.

Clinical significance: These two phases performed one after the other in the early permanent dentition were beneficial for the patient, and due to good results obtained in phase I, phase II with fixed appliances was simplified, focusing on small details of dental movements. The total time of treatment was 21 months.

Keywords: Andresen activator, Class II division 1, Functional appliance, Interception.

How to cite this article: Antelo OM, Meira TM, Iturralde A, Guimarães LK, Tanaka OM. Class II, Division 1 Malocclusion treated with the Andresen Appliance followed by Fixed Orthodontics. World J Dent 2018;9(3):242-248.

Source of support: Nil

Conflict of interest: None

1,2,4,5 Department of Orthodontics, Pontifícia Universidade Católica do Paraná, Curitiba, Paraná, Brazil

${ }^{3}$ Private Practice, Santa Cruz de la Sierra, Bolivia

Corresponding Author: Orlando M Tanaka, Department of Orthodontics, Pontifícia Universidade Católica do Paraná Curitiba, Paraná, Brazil, e-mail: tanakaom@gmail.com

\section{INTRODUCTION}

Approximately 25 to $30 \%$ of children have a class II malocclusion. Mandibular retrognathism is the most common single characteristic in class II malocclusions. ${ }^{1}$ The best way for interception and correction is to target the source of the problem and try to reduce the increased overjet and overbite, and, if possible, improve the amount and direction of mandibular growth. ${ }^{2}$ Class II functional appliance therapy focuses on reducing increased overjet and overbite, retraining the perioral musculature, and establishing good conditions for mandible growth (if the patient had one) during pubertal growth spurt. ${ }^{3}$ There are several functional devices like Bionator, Frankel II, Twin Block, and the Andresen activator that contribute to the mechanism of class II correction. ${ }^{4}$

The Andresen activator functional appliance consisted of a monoblock that during closing induces a forward position of the mandible as part of the therapeutic mechanism of correction. ${ }^{5}$ This action in the postural change of the mandible and the muscles can lead to favorable skeletal and dental changes. ${ }^{6}$

Thus, the objective of this work is: (1) to describe a class II, division 1 malocclusion treated with the Andresen activator in a growing patient followed by comprehensive orthodontic fixed appliances and (2) to take advantage of both approaches performed immediately one after the other in adolescence to obtain better and stable results without tiring the patient and parents, prolonging the treatment time.

\section{CASE REPORT}

\section{Diagnosis and Etiology}

A 13-year-old girl came with her mother for orthodontic consultation with the chief complaint of large overjet and deep overbite. The mother desired that her daughter would improve her dental and facial esthetics. No specific medical problems or temporomandibular joint symptoms were observed in the clinical examination. The patient had a dental and skeletal class II malocclusion, the overjet was $6 \mathrm{~mm}$ and the overbite was $70 \%$. She presented a midline diastema of $2 \mathrm{~mm}$, a convex profile with lip competence. The panoramic 


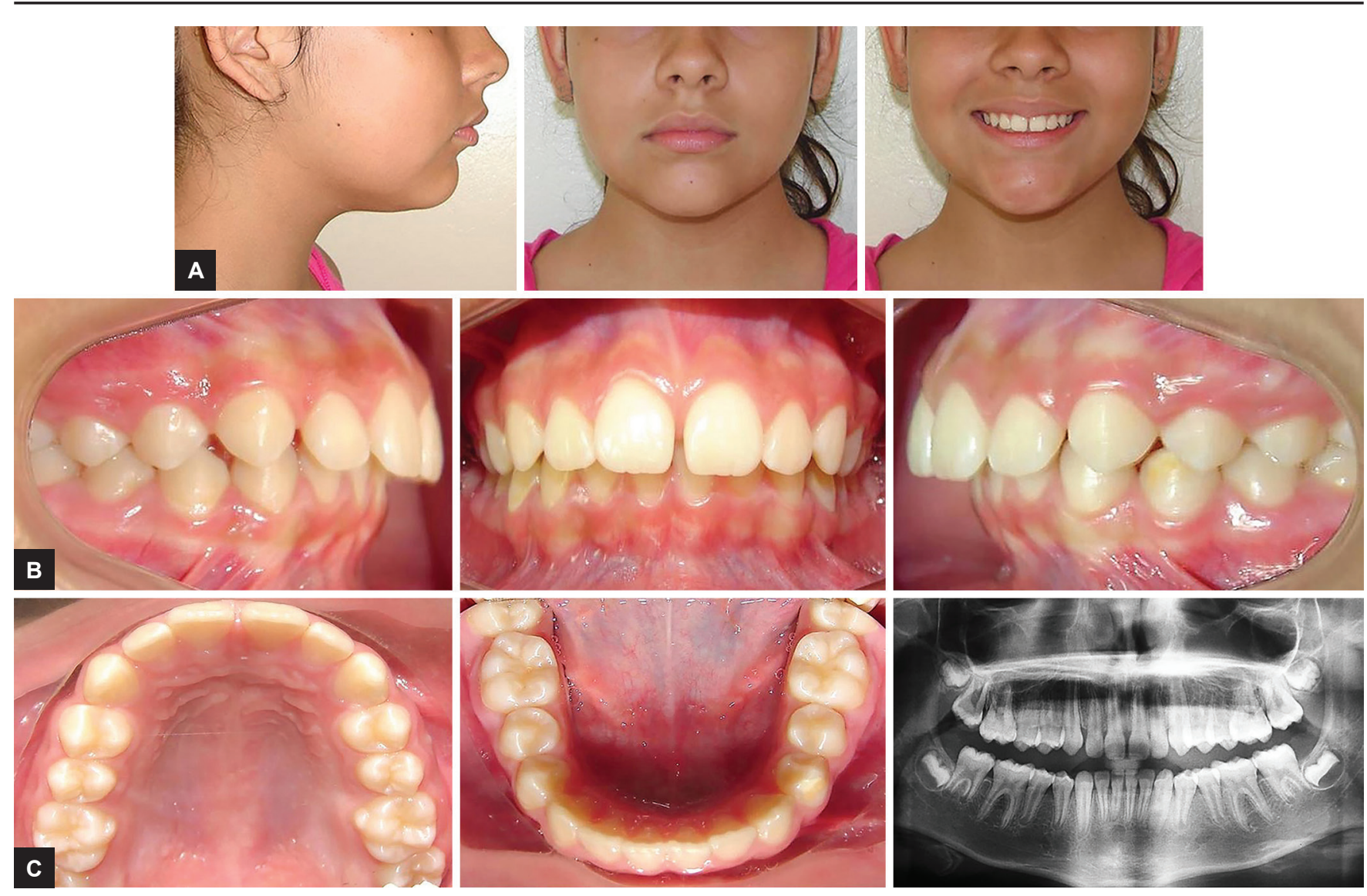

Figs $1 \mathrm{~A}$ to $\mathrm{C}$ : Phase I pretreatment facial and intraoral photos and panoramic radiograph

radiograph showed normal conditions and third molars in development (Fig. 1). The cephalometric measurements showed a class II relationship due to a retrusive mandible (Table 1).

Table 1: Cephalometric measurements

\begin{tabular}{lllll}
\hline Measurements & Initial & $\begin{array}{l}\text { Final } \\
\text { phase I }\end{array}$ & $\begin{array}{l}\text { Final } \\
\text { phase II }\end{array}$ & Follow-up \\
\hline SNA angle $\left(^{\circ}\right)$ & 83 & 82 & 82 & 82 \\
SNB angle $\left(^{\circ}\right)$ & 77 & 77 & 76.5 & 76.5 \\
ANB angle $\left(^{\circ}\right)$ & 6 & 5 & 5.5 & 5.5 \\
Ao-Bo $(\mathrm{mm})$ & 1 & -1.5 & -1 & 0 \\
Facial angle $\left(^{\circ}\right)$ & 86 & 89 & 88 & 88 \\
Convexity $\left(^{\circ}\right)$ & 15 & 11 & 12 & 12 \\
Frankfort mandibular & 23 & 24 & 22 & 22 \\
angle $\left({ }^{\circ}\right)$ & & & & \\
GoGn-SN $\left(^{\circ}\right)$ & 32 & 33 & 33 & 34 \\
Y-axis $\left({ }^{\circ}\right)$ & 60.5 & 59 & 60 & 59.5 \\
1-NA $(\mathrm{mm})$ & 3.5 & 2.5 & 2.5 & 2 \\
1-NA $\left({ }^{\circ}\right)$ & 24 & 18 & 17 & 17.5 \\
1-NB $(\mathrm{mm})$ & 7.5 & 7 & 9 & 8 \\
1-NB $\left({ }^{\circ}\right)$ & 32.5 & 34.5 & 35 & 34 \\
Incisor mandibular & 103 & 103.5 & 105 & 104 \\
plane angle & & & & \\
Interincisal angle $\left({ }^{\circ}\right)$ & 117 & 122 & 121 & 122 \\
LS-L $(\mathrm{mm})$ & 2 & 1.5 & 1.5 & 1 \\
LI-L $(\mathrm{mm})$ & 0.5 & 1 & 1.5 & 1 \\
Z-angle $\left({ }^{\circ}\right)$ & 70.5 & 72 & 70 & 71.5 \\
\hline
\end{tabular}

\section{Treatment Objectives}

The treatment objectives were to reduce the increased overjet and overbite, obtain class I dental relationship, and improve the profile.

\section{Treatment Alternatives}

- Perform functional appliance therapy to reduce the increased overjet and deep overbite, and if possible improve the amount of growth of the mandible during the pubertal growth spurt. Thus, the profile will improve as will the class II relationship, followed by comprehensive orthodontic fixed appliances.

- Headgear placement to distalize the maxillary molars to obtain a class I relationship followed by comprehensive orthodontic fixed appliances.

- Bonding fixed appliances, aligning, and leveling the deep overbite, and correcting the class II relationship with class II elastics.

- Bonding fixed appliances and extractions of maxillary first premolars to retract the upper anterior segment, obtaining a class I relationship and proper overjet and overbite.

\section{Treatment Progress}

Treatment alternatives were explained to the patient's mother and consent was obtained. The treatment plan 


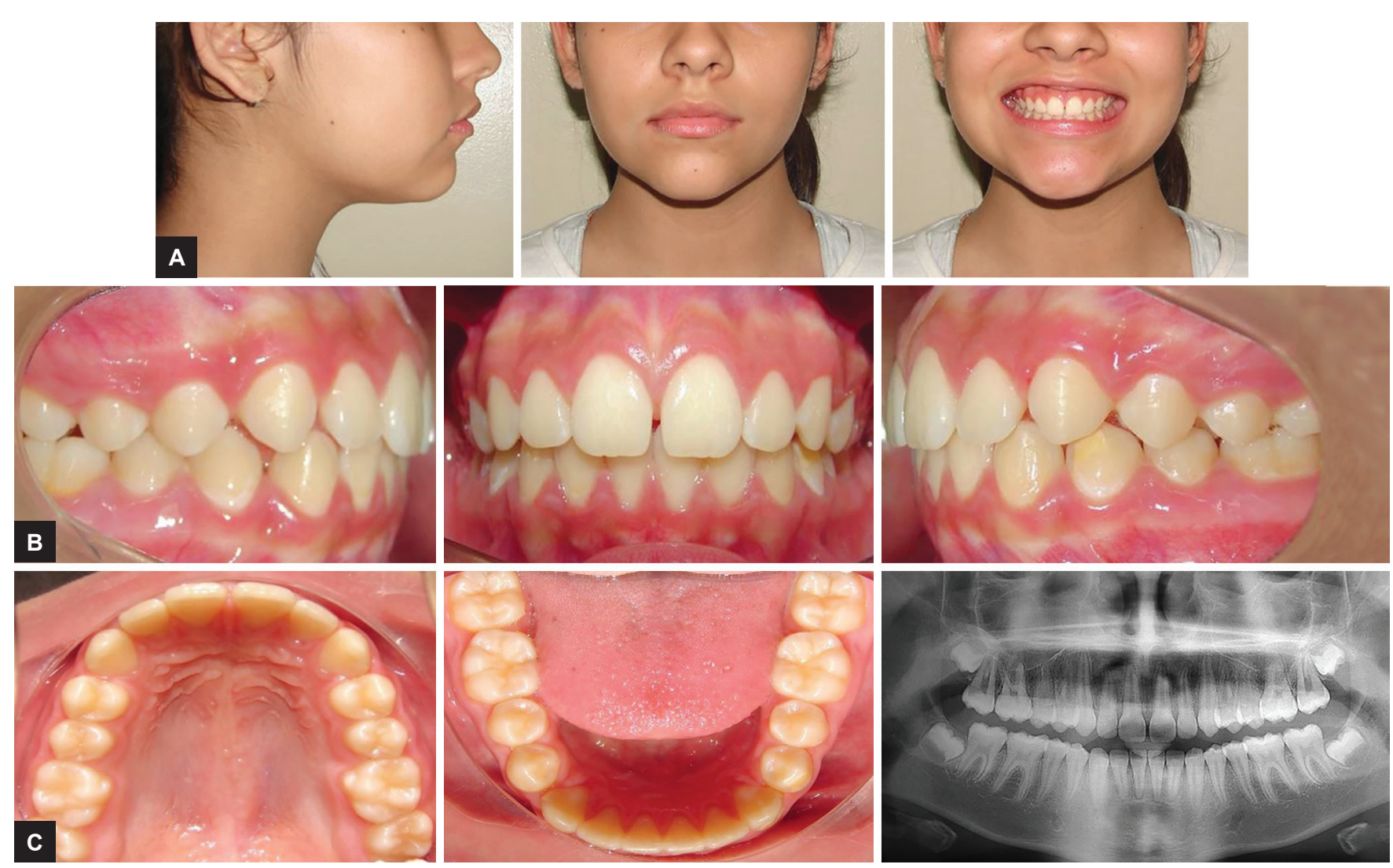

Figs 2A to C: Phase I final and phase II pretreatment facial and intraoral photos and panoramic radiograph

chosen was performing functional appliance therapy followed by comprehensive fixed appliances. The Andresen activator (Figs 2 and 3) was used for a period of 9 months from 10 to 12 hours per day during afternoons and nights, and the overjet and overbite were reduced to normal parameters (Fig. 4).

\section{Treatment Results}

The phase I treatment lasted 9 months and the goals to reduce the large overjet and deep overbite to normal parameters were achieved. Clinical inspection showed that the class II, division1 malocclusion was corrected to a class I, the convex profile was also improved to a straight one, and the inferior facial height was increased (Fig. 4).

Cephalometric measurements of the patient indicate that the main changes were found at dentoalveolar component and less at the skeletal level. The upper incisors were upright and the lower incisors were slightly proclined, reducing the increased overjet (Fig. 2 and Table 1). The lower first molars and premolars erupted, increasing the lower facial height and therefore, reducing the deep overbite. The mandible underwent a positive forward and downward growth (Table 1).
After phase I was completed, phase II started immediately with $0.022 \times 0.028 \mathrm{in}$. MBT complete fixed appliances for a period of 1 year (Fig. 3C). Class II elastics were used for a period of 3 months to maintain and enhance the sagittal correction previously obtained.

At the end of the phase II, cephalometric measurements indicated that upper and lower incisors practically maintained the same inclinations in relation to the correction achieved in phase I, maintaining the overjet in normal parameters (Fig. 5). The lower facial height increased slightly and the mandible maintained its forward and downward direction of growth (Fig. 2 and Table 1).

After 1 year of retention, the occlusion was stable. Overjet and overbite, as well as the molar and canine relationships, remained unchanged. The panoramic radiograph showed that the mandibular third molars were in progress of eruption (Fig. 6). The cephalometric measurements remain stable (Fig. 2 and Table 1).

\section{DISCUSSION}

The patient in this case report presented a skeletal class II relationship, a class II, division 1 malocclusion with increased overjet and deep overbite, and a normofacial 


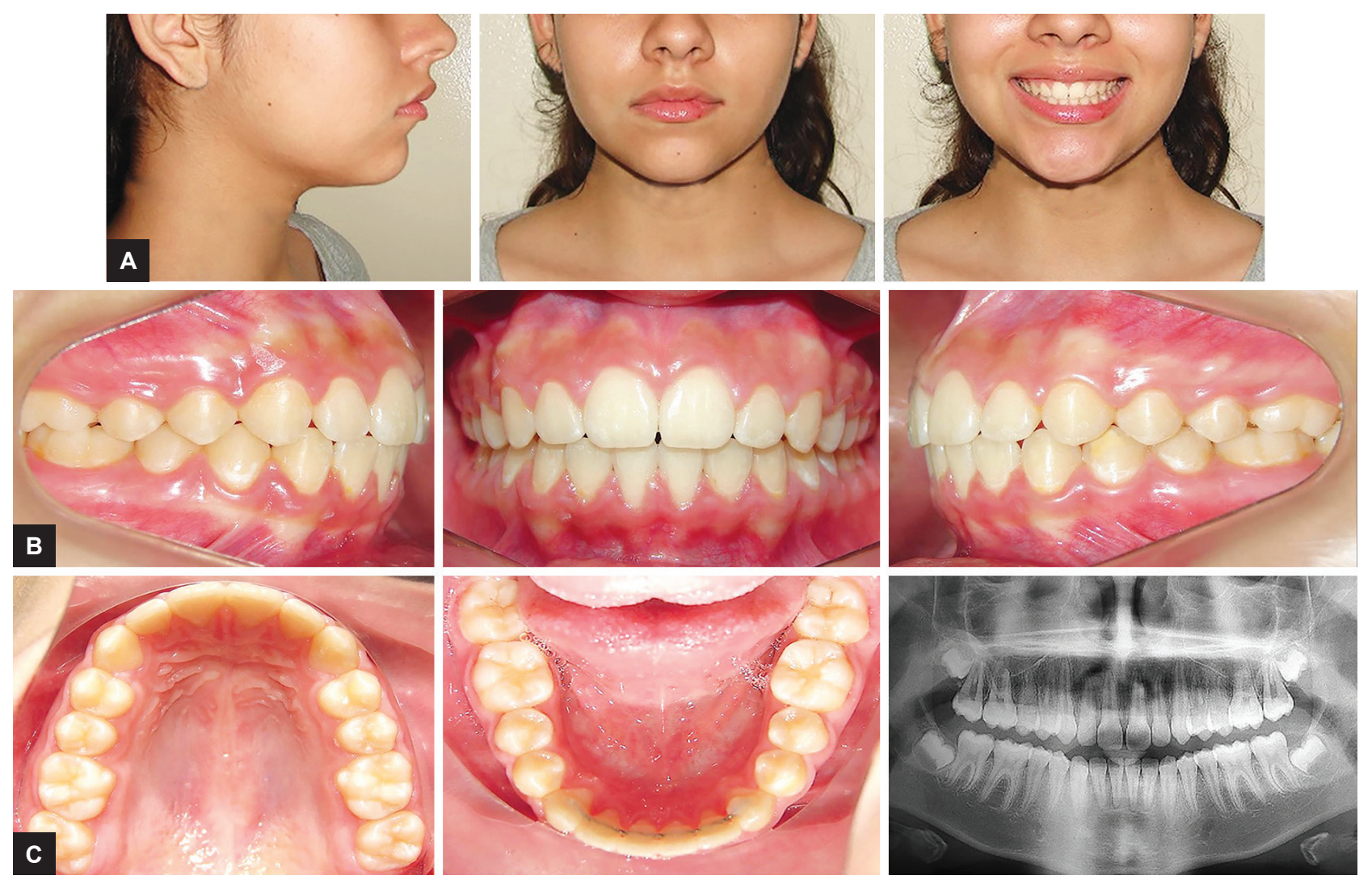

Figs 3 A to C: Andresen activator in place
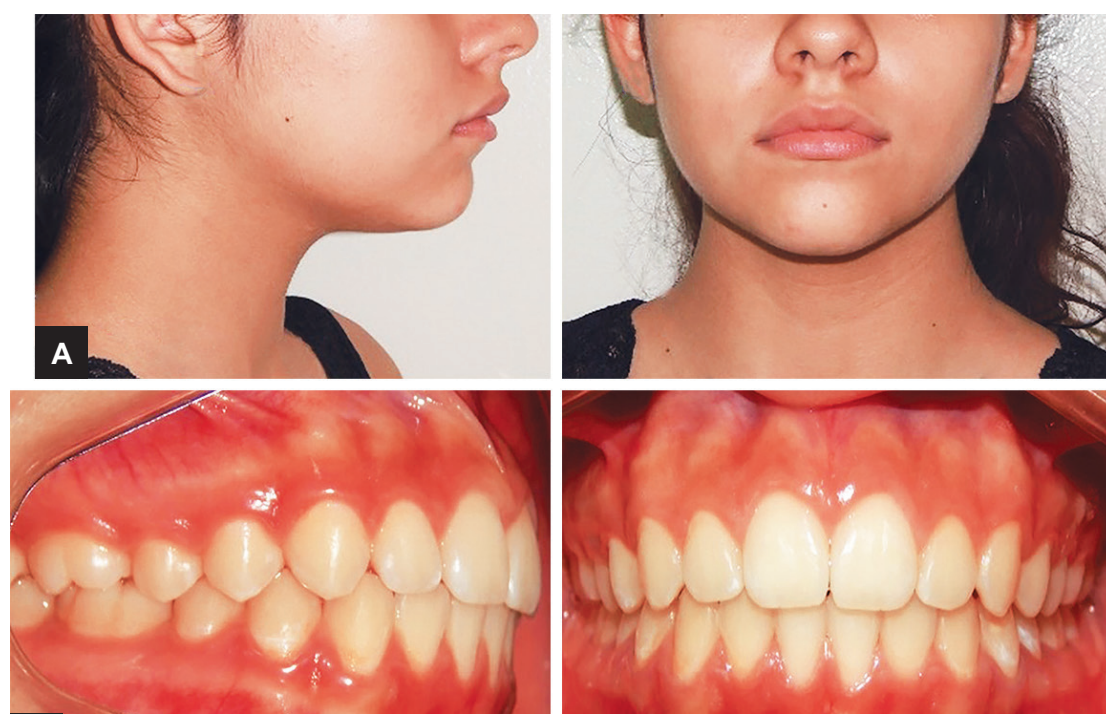

B
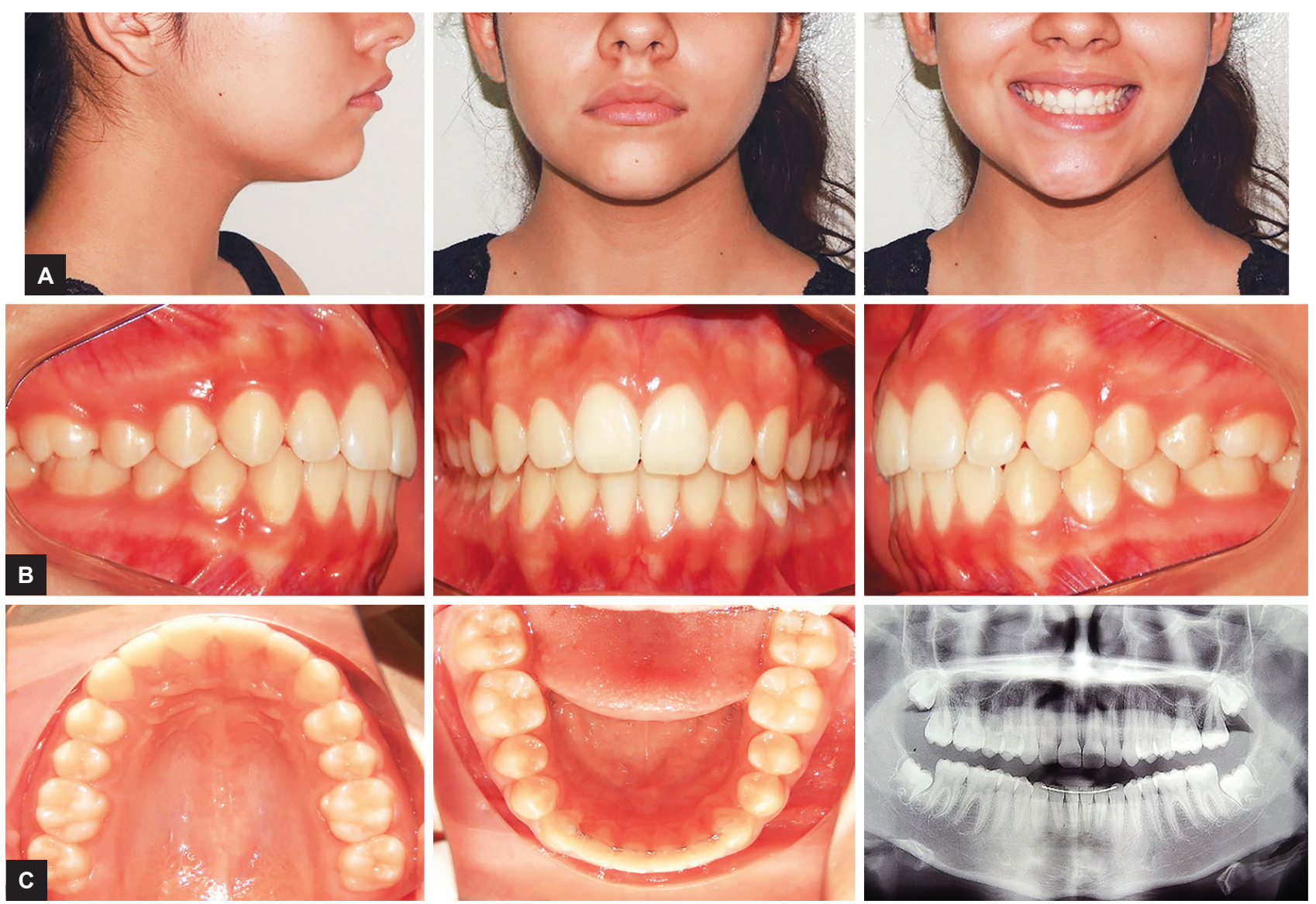

Figs 4A to C: Phase I final and phase II pretreatment facial and intraoral photos and panoramic radiograph 

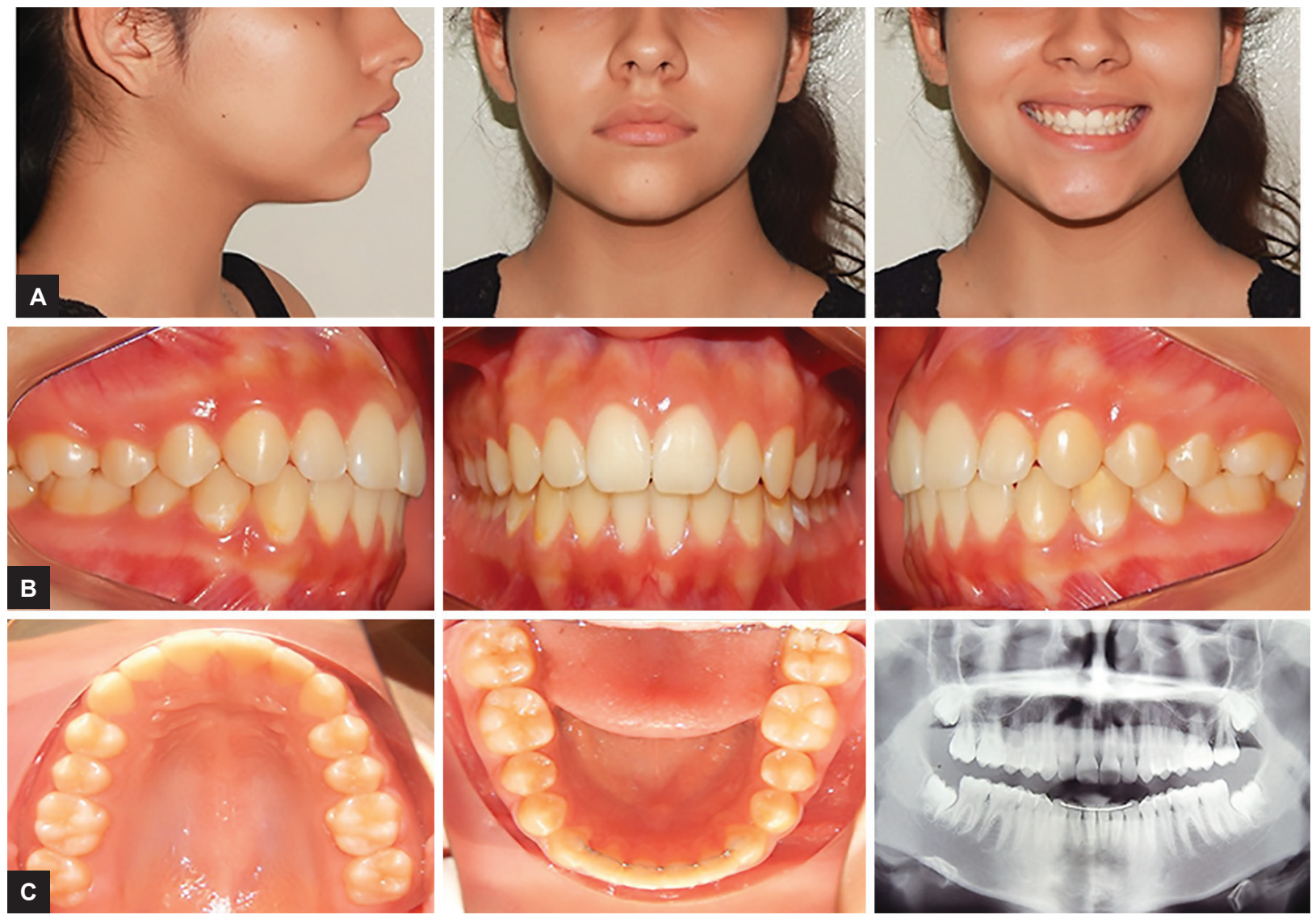

Figs 5A to C: Posttreatment facial and intraoral photos and panoramic radiograph
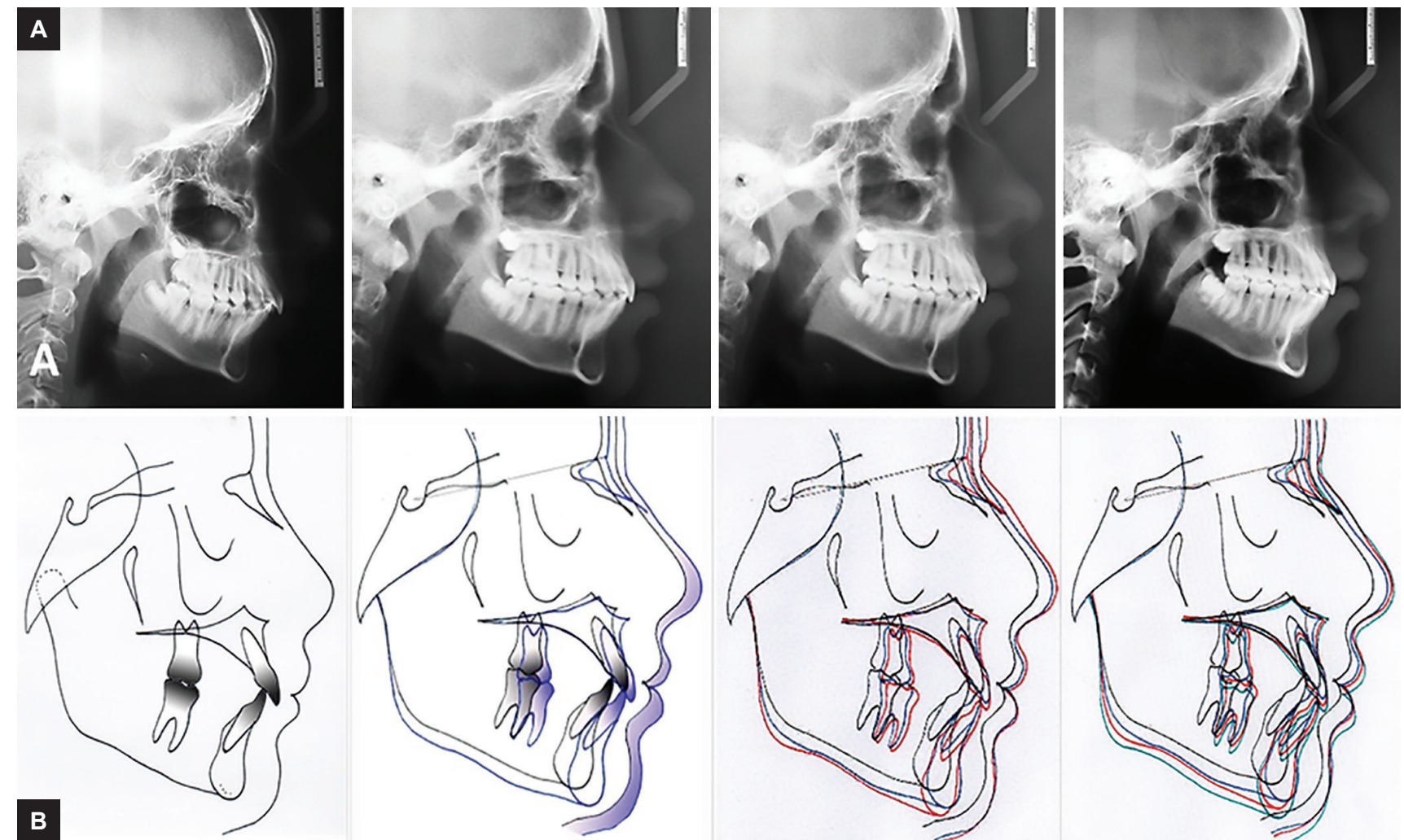

Figs 6A and B: One-year follow-up facial and intraoral photos and panoramic radiograph 
growth pattern. She wore the Andresen appliance for a period of 9 months during afternoons and nights, approximately 10 to 12 hours.

According to Pancherz et $\mathrm{al}^{7}$ functional appliance therapy stimulates the growth of the mandible and restrains the growth of the maxilla. In opposition, Cozza et $\mathrm{al}^{8}$ reported that there is no scientific evidence corroborating that a functional appliance can stimulate the growth of the mandible; and the results that corroborate these data are weak and lack a properly conducted methodology.

The cephalometric measurements of our patient in phase I indicated that the main changes were observed at the dentoalveolar component and to a lesser extent at the skeletal level. The maxillary incisors were upright and the mandibular incisors were slightly proclined, reducing the increased overjet. The first mandibular molars and premolars erupted, increasing the lower facial height and reducing the deep overbite; the mandible underwent a slight positive forward and downward growth. These findings are in concordance with Perillo et al, ${ }^{9}$ sustaining that the main correction is produced at the dentoalveolar level.

The treatment in phase I reduced the increased overjet and overbite to normal parameters and improved the soft tissue profile in our patient. The Andresen appliance is effective in reducing the increased overjet and overbite in class II, division 1 malocclusions with normal or hypodivergent growth pattern in growing patients. ${ }^{10}$ The recommended age for Andresen appliance placement is at the end of the mixed dentition or at the beginning of the complete permanent dentition, between 11 and 13 years. ${ }^{11}$ Generally, the treatment duration with an Andresen appliance is from 6 to 9 months, with the objective of reducing the increased overjet and overbite and achieving a suitable seal of the lips, ${ }^{12}$ as seen in the present clinical case.

Preferably, it is better not to treat class II, division 1 malocclusion in growing patients at an early age, since there is still mandibular growth potential at ages 11 to 13 years; and a treatment started very early increases the treatment time and wears out the patient and the parents. ${ }^{13}$ In some individuals, it may be beneficial to initiate early treatment because of special circumstances, such as bullying or the risk of trauma of incisors by accidents. ${ }^{14}$

Phase I lasted 9 months, followed immediately by phase II with complete fixed appliances for an extra period of 12 months. The total time of treatment was 21 months. These two phases performed one after the other in the early permanent dentition was beneficial for the patient, since in phase I, the increased overjet and overbite were reduced, allowing for normal development and normal function of the lips. Due to good results obtained in phase I, phase II with fixed appliances was simplified, focusing on small details of dental movements. ${ }^{15}$

\section{CONCLUSION}

The Andresen appliance used in phase I was effective in reducing the increased overjet and overbite in this class II, division 1 malocclusion. Changes occurred mainly at the dentoalveolar level with a marked improvement of the facial profile favoring the orthodontic treatment in phase II with good and stable results.

\section{REFERENCES}

1. McNamara JA Jr. Components of Class II malocclusion in children 8-10 years of age. Angle Orthod 1981 Jul;51(3): 177-202.

2. Chen JY, Will LA, Niederman R. Analysis of efficacy of functional appliances on mandibular growth. Am J Orthod Dentofacial Orthop 2002 Nov;122(5):470-476.

3. Woźniak K, Piątkowska D, Szyszka-Sommerfeld L, Buczkowska-Radlińska J. Impact of functional appliances on muscle activity: a surface electromyography study in children. Med Sci Monit 2015 Jan;21:246-253.

4. Koretsi V, Zymperdikas VF, Papageorgiou SN, Papadopoulos MA. Treatment effects of removable functional appliances in patients with Class II malocclusion: a systematic review and meta-analysis. Eur J Orthod 2015 Aug;37(4):418-434.

5. Bishara SE, Ziaja RR. Functional appliances: a review. Am J Orthod Dentofacial Orthop 1989 Mar;95(3):250-258.

6. Perinetti G, Primozic J, Franchi L, Contardo L. Treatment effects of removable functional appliances in pre-pubertal and pubertal class II patients: a systematic review and meta-analysis of controlled studies. PLoS One 2015 Oct;10(10):e0141198.

7. Pancherz H, Ruf S, Kohlhas P. "Effective condylar growth" and chin position changes in Herbst treatment: a cephalometric roentgenographic long-term study. Am J Orthod Dentofacial Orthop 1998 Oct;114(4):437-446.

8. Cozza P, Baccetti T, Franchi L, De Toffol L, McNamara JA Jr. Mandibular changes produced by functional appliances in Class II malocclusion: a systematic review. Am J Orthod Dentofacial Orthop 2006 May;129(5):599:599.e1-599.e12.

9. Perillo L, Femiano A, Palumbo S, Contardo L, Perinetti G. Skeletal and dental effects produced by functional regulator-2 in pre-pubertal class II patients: a controlled study. Prog Orthod 2013 Jul;14:18.

10. Franchi L, Pavoni C, Faltin K Jr, McNamara JA Jr, Cozza P. Long-term skeletal and dental effects and treatment timing for functional appliances in Class II malocclusion. Angle Orthod 2012 Mar;83(2):334-340.

11. von Bremen J, Pancherz H. Efficiency of early and late Class II Division 1 treatment. Am J Orthod Dentofacial Orthop 2002 Jan;121(1):31-37.

12. Bennett, JC. Orthodontic management of uncrowded class II division 1 malocclusion in children. London: Elsevier Health Sciences; 2006. 
13. Tulloch JF, Proffit WR, Phillips C. Outcomes in a 2-phase randomized clinical trial of early Class II treatment. Am J Orthod Dentofacial Orthop 2004 Jun;125(6): 657-667.

14. Årtun J, Behbehani F, Al-Jame B, Kerosuo H. Incisor trauma in an adolescent Arab population: prevalence, severity, and occlusal risk factors. Am J Orthod Dentofacial Orthop 2005 Sep;128(3):347-352.

15. Franchi L, Baccetti T. Prediction of individual mandibular changes induced by functional jaw orthopedics followed by fixed appliances in Class II patients. Angle Orthod 2006 Nov;76(6):950-954. 